\title{
Avulsão parcial de casco em equino com crescimento laminar em aparente fluxo ascendente
}

\section{Partial avulsion of equine hoof with laminar growth in apparent ascending laminar flow}

\author{
Luiza de Siqueira Almeida Reis", Rita de Cássia Campebell, Antônio Carlos Lopes Câmara, Antônio Raphael \\ Teixeira Neto, Márcio Botelho de Castro, Tais Meziara Wilson, Igor Louzada Moreira \\ Universidade de Brasília (UnB), Brasília, DF, Brasil
}

\section{Resumo}

Avulsão do casco é descrita como uma laceração aguda ou ocasionada por lesões crônicas por traumas repetitivos, podendo ser completa, com perda total dos tecidos, ou incompleta, na qual uma borda do casco permanece intacta. A parede do casco, região coronária, sola, falange distal, lâminas e a articulação interfalangeana distal podem estar envolvidas. Neste trabalho, relata-se o caso de um equino, SRD, macho, adulto, de aproximadamente 15 anos e com $285 \mathrm{~kg}$, encaminhado ao hospital veterinário apresentando ferida com secreção purulenta, tecido necrosado e avulsão na porção dorsal da pele e região coronária do membro pélvico direito, além de edema distal da articulação metatarso-falangeana e claudicação. Na avaliação física, observou-se extensiva lesão traumática no casco do membro pélvico direito, com perda de parte da muralha no aspecto dorsal, tecido ulcerativo e necrótico, com incrustações compactas e de odor fétido, presença de miíase na sola e claudicação de grau 5. A terapêutica aplicada associada à abordagem cirúrgica promoveu evolução satisfatória da ferida podal, com progressiva eclosão do estojo córneo em direção oposta ao que é comumente observado, isto é, a cicatrização adquiriu uma oclusão advinda da região distal, próxima à pinça do casco em direção à coroa, adquirindo fornecimento constante de novas células na região lamelar, gerando um aparente fluxo laminar ascendente e considerável diminuição de secreção e redução da claudicação para grau 3.

Palavras-chave: Laceração. Reação periosteal. Perfusão regional. Venografia.

\begin{abstract}
Hoof avulsion is described as an acute laceration or chronic injury resulting from repetitive trauma that may be complete, with total tissue loss, or incomplete, in which an edge of the hoof remains intact. The lesion may involve hoof wall, coronary region, sole, distal phalanx, laminae, and the distal interphalangeal joint. This study reports the case of a mixed breed, 15-year-old male horse, weighing $285 \mathrm{~kg}$
\end{abstract}


that was seen at the veterinary hospital with a purulent wound, necrotic tissue and avulsion in the dorsal portion of the skin and coronary region of the right pelvic limb, as well as an edema in the distal to the metatarsal-phalanx joint and lameness. The physical evaluation showed an extensive traumatic injury on the hoof of the right pelvic limb, with partial loss of the dorsal wall, presence of ulcerative and necrotic tissue, with compact inlays and foul smelling, myiasis in the sole as well, and lameness grade 5/5. The surgery associated with therapeutic treatment promoted a satisfactory evolution of the foot wound, with progressive hatching of the corneal case in the opposite direction to that commonly observed, that is, the healing acquired an occlusion from the distal region, close to the hull forceps toward the crown, acquiring a constant supply of new cells in the lamellar region, generating an apparent ascending laminar flow and considerable decrease of secretion while lameness decreased to grade $3 / 5$.

Keywords: Laceration. Periosteal reaction. Regional perfusion. Venography.

\section{Introdução}

0 casco do equino cresce durante toda a vida do animal, substituindo o que é perdido pelo desgaste natural que ocorre na superfície do solo. A regeneração contínua do casco ocorre na coroa, onde as células germinativas, as chamadas células basais epidérmicas, produzem populações de "célulasfilhas", que são as células produtoras de queratina, as quais se maturam e se queratinizam, adicionando-se continuamente à região proximal da parede do casco (Pollitt, 2008). Segundo Leach (1980), processos mitóticos também ocorrem similarmente nas lâminas epidérmicas primárias (LEPs).

Devido à proximidade com o solo, feridas nestas localidades se contaminam por fezes e sujidades e, caso o cavalo não seja tratado prontamente, a contaminação resultará em infecção, com descolamento das lâminas epidérmicas e dérmicas. Complicações subsequentes incluem infecção das lâminas expostas, fratura ou perda parcial da falange distal, e inflamação da articulação interfalangeana distal ou da bainha digital do tendão flexor (Schumacher e Stashak, 2008).
Laceração e avulsão de uma porção do casco são injúrias comuns, sendo causadas frequentemente por objetos pontiagudos, resultando em claudicação permanente e, em alguns casos, em eutanásia. Uma porção da cápsula do casco pode se separar total ou parcialmente; nesta última, o casco ainda se encontra conectado, em algum grau, à borda coronária. A avulsão pode envolver estruturas profundas, como a falange distal ou a articulação interfalangeana distal (Schumacher e Stashak, 2008).

Injúrias perfurantes do dígito são comuns e podem ter graves consequências, como osteíte e osteomielite infecciosas, se não observadas e tratadas precocemente. No cavalo adulto, a osteíte infecciosa é comum na falange distal por não possuir cavidade medular, geralmente relacionada a trauma (Butler et al., 2017).

Em consequência de fratura, trauma, infecção ou neoplasias, ocorre nova formação periosteal ou endosteal óssea resultante da inflamação do periósteo ou endósteo que, por possuir uma única camada de periósteo fibroso, que se afina distalmente, é menos óbvia do que em outras localizações (Butler et al., 2017).

0 crescimento do casco éimpactado por múltiplos fatores, incluindo o fluxo sanguíneo periférico ao dígito, distribuição de peso no casco, clima, nutrição, nível de exercício, metabolismo, condição física, parasitismo e idade (Butler et al., 2017). A muralha em si é avascular e completamente celular (Bertram e Gosline, 1987). Quaisquer fluídos ou nutrientes necessários são providenciados por difusão através da membrana basal, que se encontra próxima à derme vascularizada. As células do epitélio germinativo são produzidas na banda coronária e, conforme a muralha cresce, migram distalmente para a pinça do casco (Bertram e Gosline, 1987).

Para determinarem precisamente onde ocorre a proliferação celular epidérmica na muralha do casco, Daradka e Pollitt (2004) calcularam um índice proliferativo (IP) para as células basais da banda coronária, das lâminas e da pinça da muralha dorsal do casco em pôneis. Os autores observaram que, distalmente às zonas de crescimento da região proximal da muralha do casco, os valores de IP das lâminas foram muito menores. A evidência do suprimento constante de novas células na região 
laminar, gerando um fluxo laminar descendente, não foi fornecido por este estudo, porém as poucas células proliferativas detectadas na principal região laminar possuíam distribuição irregular e estavam localizadas nas lâminas epidérmicas primárias (LEP). As células epidérmicas e suas membranas basais adjacentes estão constantemente respondendo aos estresses e fissuras de crescimento e locomoção da liberação das metaloproteinases (MMPs) para alcançar qualquer reorganização celular necessária (Pollitt, 2004).

\section{Relato do caso}

Foi encaminhado ao Hospital Veterinário de Grandes Animais da Universidade de Brasília (HVET- UnB) um equino, macho, SRD, de aproximadamente 15 anos. À avaliação clínica, apresentava-se em estação, calmo, hidratado; linfonodos não reativos, mucosas aparentes normocoradas, tempo de preenchimento capilar (TPC) de 2 segundos; frequência cardíaca de $40 \mathrm{bpm}$, frequência respiratória de $20 \mathrm{mpm}$ e temperatura de $37,8^{\circ} \mathrm{C}$.

No exame dermatológico, notou-se lesão ulcerativa e granulosa com margem irregular, presença de miíase e necrose tecidual no casco do membro pélvico direito (MPD), com perda de parte da muralha do casco, indicando possível avulsão parcial ou pododermatite séptica prévia, a qual se agravou (Figura 1). Pelo fato da causa primária não ser conhecida, as suspeitas clínicas se limitaram a lesões podais interrelacionadas. Neste caso, avulsão, osteíte podal, pododermatite séptica, injúria traumática, como crancos, foram incluídas na lista de principais suspeitas.

o tratamento clínico envolveu limpeza do ferimento (Figura 2) com solução de iodopovidona (PVPI) diluído a 1\% (1:100) e aplicação tópica de nitrofural com açúcar. Realizou-se bandagem compressiva inicialmente no primeiro dia. Nos dias seguintes, foi aplicada bandagem sem compressão, diariamente, além do ferrageamento corretivo oval do casco acometido. Os fármacos utilizados foram soro antitetânico, via intramuscular (IM), fenilbutazona, por via intravenosa (IV), 4,4 mg. $\mathrm{kg}^{-1}$, q24h, quatro dias, gentamicina, IV, 6,6 mg. $\mathrm{kg}^{-1}$, q24h, cinco dias, e benzilpenicilina benzatina $30.000 \mathrm{UI} /$ kg IM, com intervalos de $48 \mathrm{~h}$, totalizando três aplicações. Adicionalmente, optou-se por realizar o debridamento do tecido necrótico contaminado, permitindo drenagem adequada, seguido de perfusão intravenosa regional na veia safena pela associação de $25 \mathrm{~mL}$ de gentamicina com $25 \mathrm{~mL}$ de sulfóxido de dimetilo (DMSO), diluídos em $250 \mathrm{~mL}$ de solução isotônica, durante aproximadamente 5 minutos, mantendo-se o torniquete por 30 minutos após a infusão da solução.

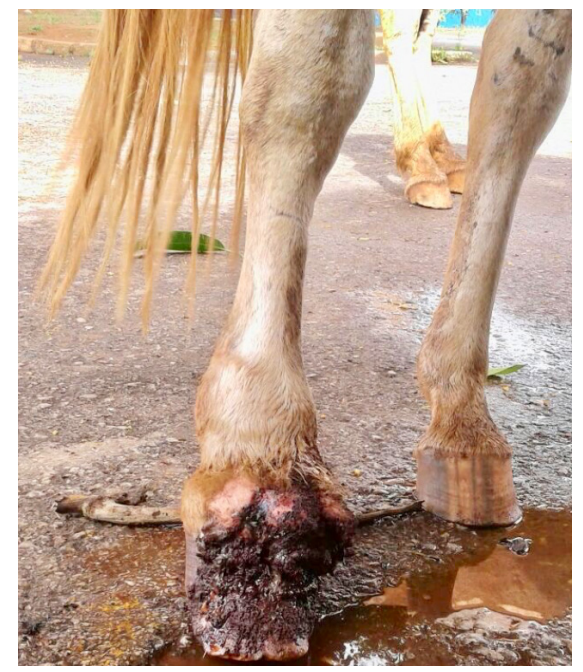

Figura 1 - Ferida podal em membro pélvico direito apresentando irregularidade, graves áreas de necrose e miíase. Imagem do primeiro dia de encaminhamento do animal ao hospital.

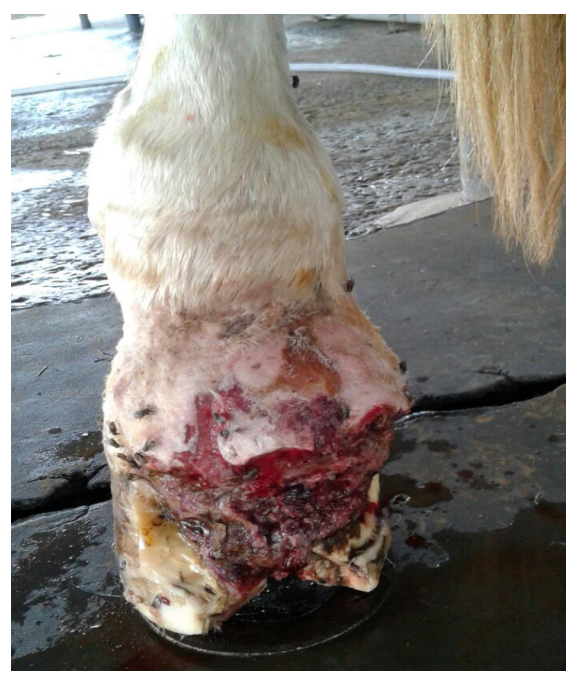

Figura 2 - Extensão da lesão após debridamento cirúrgico, em ferida podal, no membro pélvico direito. 
Foram realizadas cinco avaliações radiográficas. 0 primeiro exame indicou, nas projeções dorsoplantar (DPl) e látero-medial (LM) de MPD, completa desconfiguração da terceira falange, perda de definição de suas margens, bem como do sesamóide distal, além de reação periosteal com

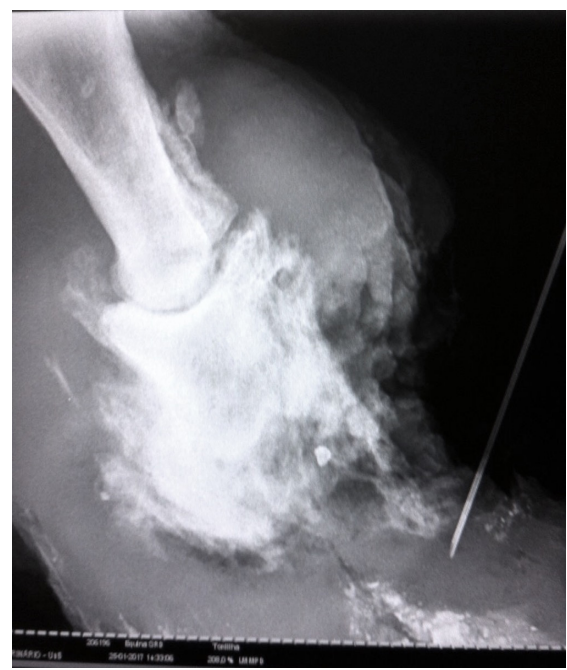

Figura 3A - Projeção latero-medial do membro pélvico direito, observando-se completa desconfiguração com radiopacidade da terceira falange, perda de definição de suas margens, bem como do sesamoide distal.

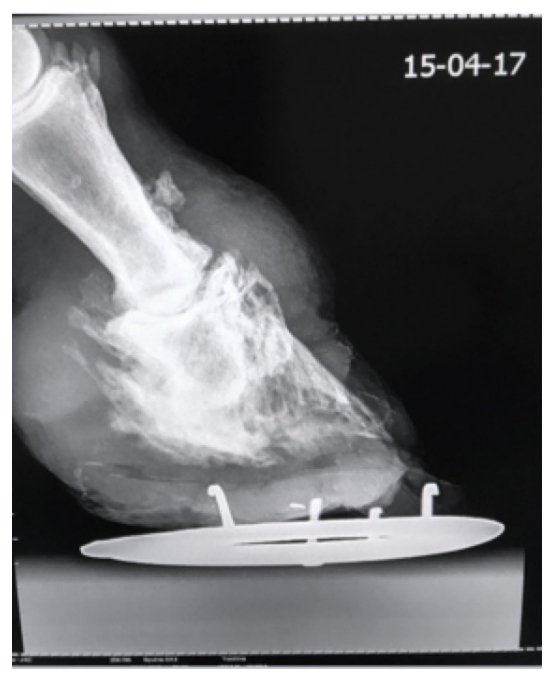

Figura 4A - Projeção látero-medial de membro pélvico direito, realizada 60 dias após início do tratamento, indicando início de remodelamento ósseo entre as falanges e contínua reação tecidual. Nota-se a presença da ferradura corretiva. perda de contornos parciais da falange média e bordas sem definição na falange proximal (Figuras 3A e B). Após 60 dias de tratamento, em uma segunda avaliação, pôde-se constatar início de processo anquilótico entre as falanges (Figura 4A) e visível redução da reação tecidual (Figura 4B).

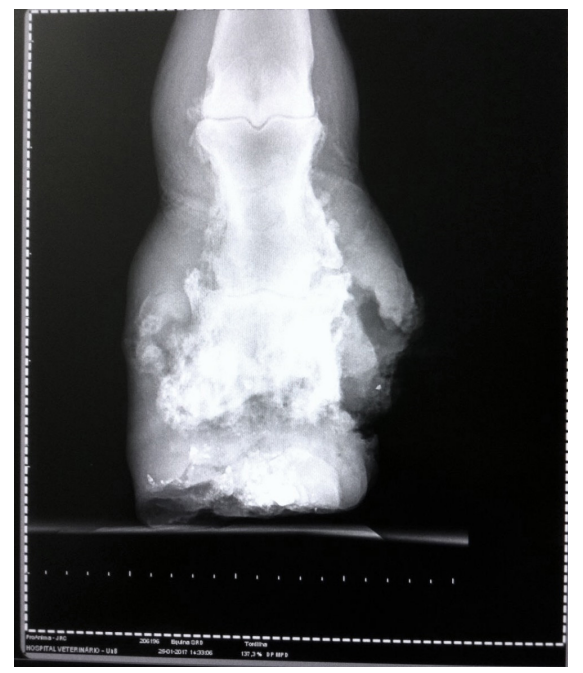

Figura 3B - Projeção dorso-plantar do membro pélvico direito, observando-se reação periosteal com perda de contornos parciais da falange média e bordas sem definição na falange proximal.

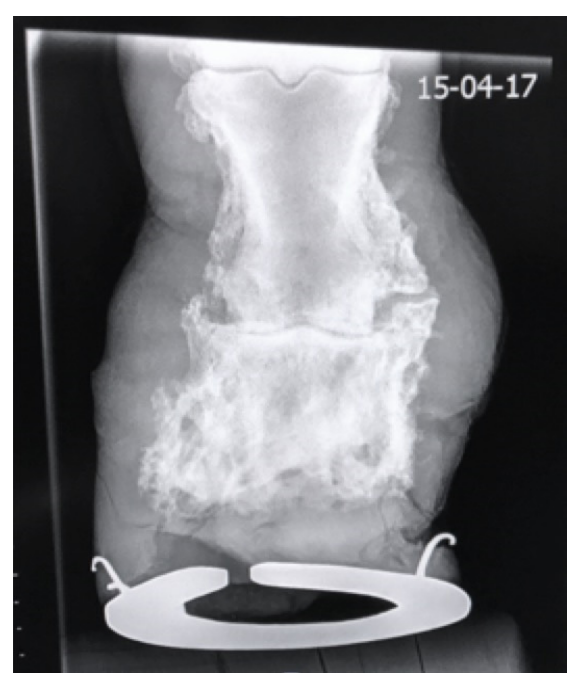

Figura 4B - Projeção dorso-plantar realizada 60 dias após início de tratamento, indicando processo de remodelamento e de anquilose entre as falanges média e distal. 
Após uma semana, optou-se por realizar exame venográfico para avaliação da vascularização distal do membro. Nesta técnica, um torniquete foi colocado proximalmente à estrutura infectada, de forma a possibilitar a permanência do fármaco na região acometida ao se ocluir o fluxo venoso, difundindo-o aos tecidos distais do membro.

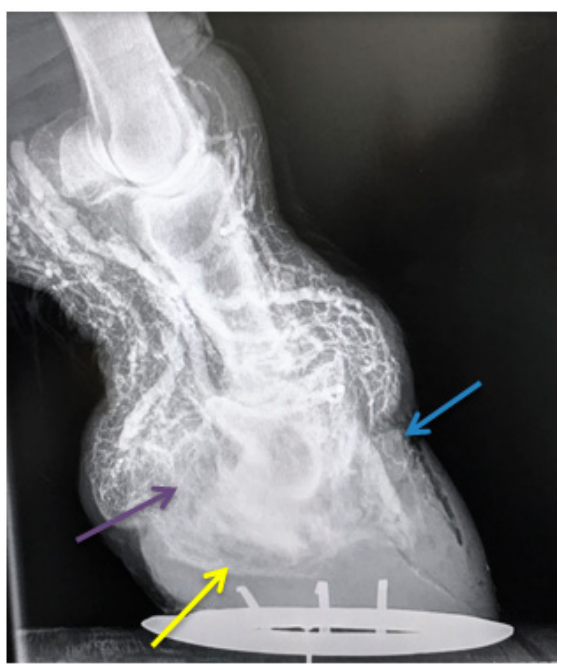

Figura 5A - Projeção látero-medial após injeção de contraste na veia digital lateral, indicando nova vascularização na área. Há déficit no preenchimento dos vasos laminares dorsais (seta azul), vasos circumflexos (seta amarela) e reorganização na região do bulbo do talão (seta roxa).

Aproximadamente um ano depois, o paciente ainda apresentava reação óssea ativa, corroborando com a suspeita de que a inflamação podal tornouse crônica. Nas figuras $6 \mathrm{~A}, \mathrm{~B}, \mathrm{C}$ e D é possível observar que houve reorganização do tecido ósseo e diminuição de reação teciual, porém ainda com presença de reações periosteais.

Para avaliação histológica, foram encaminhados dois recipientes, devidamente identificados, ao Laboratório de Patologia Veterinária (LPV) da UnB, um contendo tecido brancacento, firme, medindo 1 $\mathrm{cm} \times 3 \mathrm{~mm} \times 2 \mathrm{~mm}$, retirado da borda coronária no aspecto dorsal, e outro contendo tecido de mesmo aspecto, medindo $8 \mathrm{~mm} \times 3 \mathrm{~mm} \times 3 \mathrm{~mm}$, retirado da borda ventral coronária, ambos da região da avulsão, em solução de formol. A amostra foi clivada e colocada em cassetes identificados, sendo
Ao exame venográfico, observou-se comprometimento do plexo bulbar, vasos laminares dorsais, arco terminal e plexo coronário, indicando diminuição de perfusão do dígito e, consequentemente, diminuição de volume de sangue dentro do casco, impedindo que houvesse pressão suficiente do fluído para amortecer o impacto inicial com o solo (Figuras 5A e B).

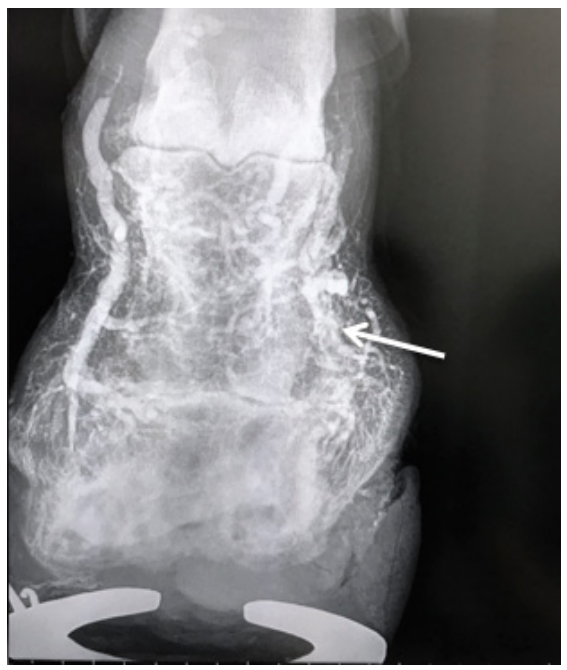

Figura 5B - Venografia digital na projeção dorso-plantar, observando-se déficit dos vasos digitais em aspecto medial (seta).

posteriormente encaminhada para processamento histopatológico.

No fragmento 1 (Figura 7A), observou-se área focalmente externa ao estrato córneo, por entre os queratinócitos, espaços claros que não se coraram (edema) e hemácias fora dos vasos (hemorragia), além de infiltrado multifocal moderado de polimorfonucleares.

No fragmento 2 (Figura 7B), observou-se, na derme superficial e profunda, infiltrado inflamatório difuso, acentuado de neutrófilos, macrófagos e eosinófilos. Notou-se perda de continuidade da epiderme com exposição da derme, a qual se mostrou encoberta por crosta eosinofílica permeada por grande quantidade de neutrófilos íntegros e degenerados, material eosinofílico amorfo e debris celulares (ulceração e necrose). 


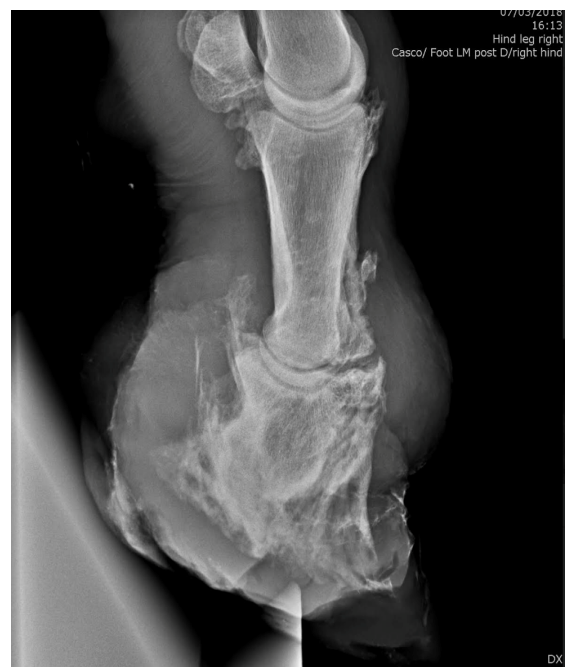

Figura 6A - Projeção látero-medial de membro pélvico direito após aproximadamente 1 ano desde a internação do paciente no hospital.

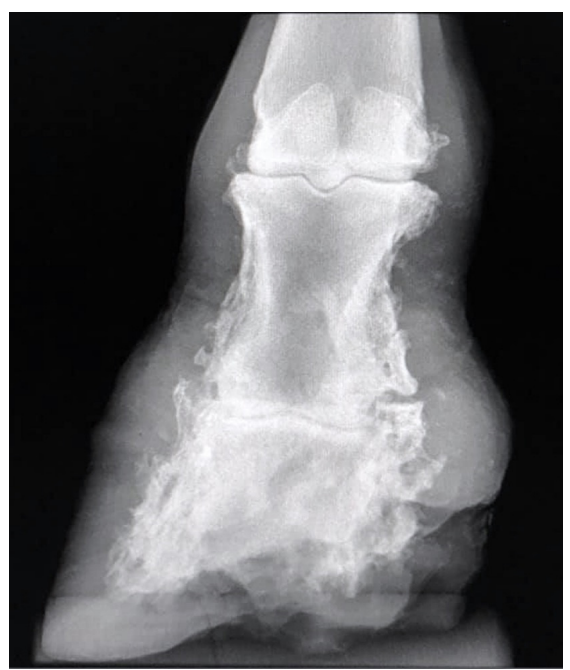

Figura 6C - Projeção dorso-plantar de membro pélvico direito um mês após realização das projeções $6 \mathrm{~A}$ e $6 \mathrm{~B}$, indicando presença de reação óssea periarticular na região da articulação metatarso-falanegana e interfalangeana proximal.

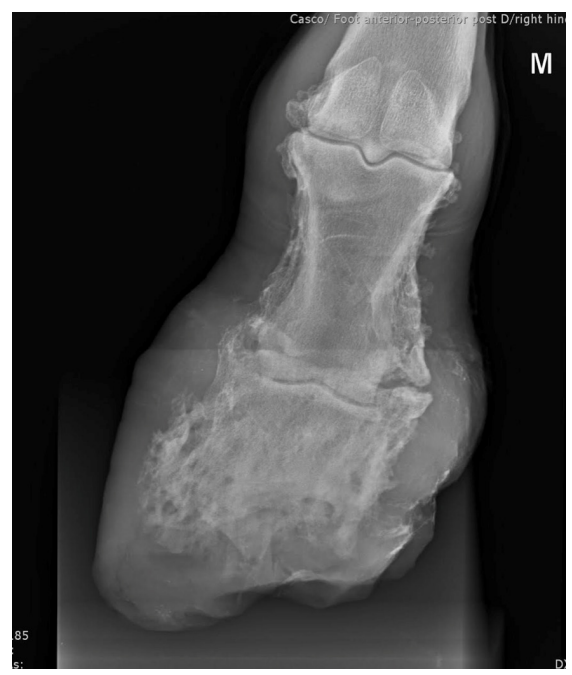

Figura 6B - Projeção dorso-plantar indicando mínima viabilidade da superfície articular da articulação interfalangeana distal.

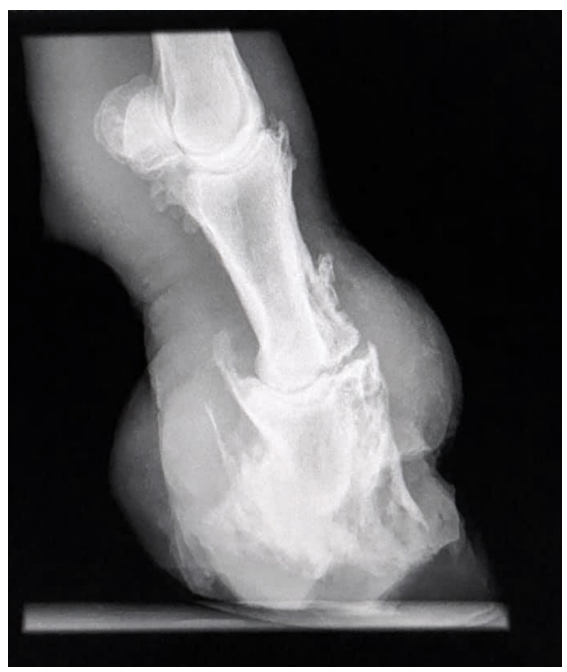

Figura 6D - Projeção látero-medial de membro pélvico direito. Apesar de haver reação ativa, as faces articulares destas estruturas ainda se apresentam razoavelmente preservadas. 


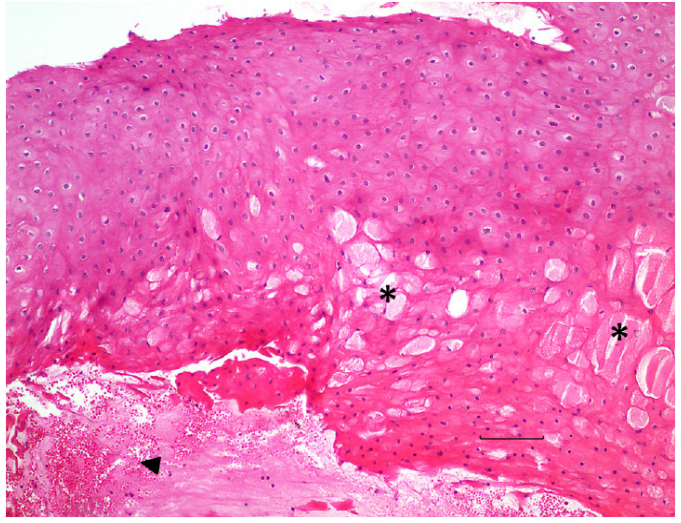

Figura 7A - Casco. Edema focalmente extenso por entre os queratinócitos $\left(^{*}\right)$ e hemorragia subcorneal (seta). HE (barra = $100 \mu \mathrm{m})$.

\section{Discussão}

Identificar a causa da ferida e presença de corpos estranhos são considerações importantes que podem influenciar no seu manejo. Histórico de vacinação contra tétano também deve ser verificado, principalmente se o cavalo estiver sendo examinado pela primeira vez.

0 envolvimento de estruturas músculoesqueléticas como articulações, tendões, ligamentos, ossos e outros sistemas, também deve ser levado em consideração. 0 debridamente cirúrgico, que foi realizado neste caso, possibilitou a identificação da extensão da lesão podal, além de viabilizar melhor suprimento sanguíneo ao local, bem como redução de carga bacteriana.

Cavalos com bom fluxo hemodinâmico apresentam melhor estrutura córnea do casco, indicando que o fluxo sanguíneo é um fator primário em fornecer os nutrientes necessários para o crescimento do mesmo (Bowker et al., 1998).

0 remodelamento da epiderme e da matriz extracelular é conhecido por envolver a liberação controlada de MMPs e seu subsequente bloqueio por inibidores teciduais específicos. As células basais da coroa do casco passam por mitose por toda a vida do cavalo, produzindo "céulas-filhas" do estrato médio, as quais maturam e queratinizam, levando até oito meses para que alcancem a superfície solear, adquirindo, portanto, um fluxo

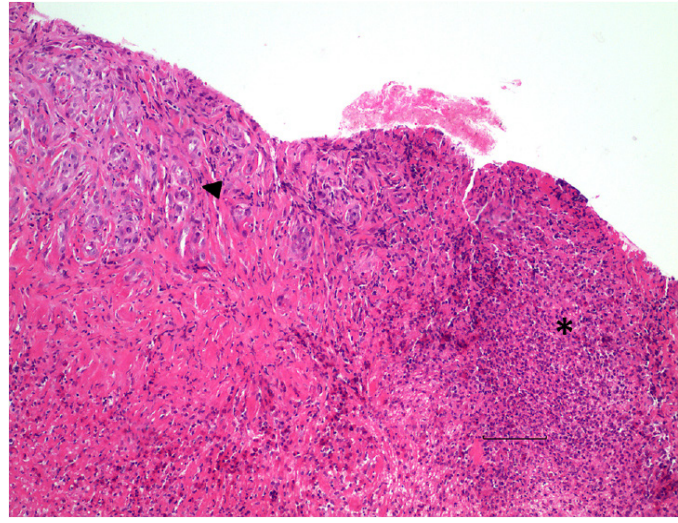

Figura 7B - Pele hirsuta. Ulceração epidérmica com infiltrado inflamatório difuso acentuado de neutrófilos, alguns eosinófilos e macrófagos (*), e área focal de proliferação fibrovascular (seta). HE (barra $=100 \mu \mathrm{m}$.)

laminar descendente (Pollitt, 2004). Neste animal, identificou-se o crescimento de novo córium e o subsequente remodelamento progressivo do estojo córneo em sentido disto-proximal, ao invés de tipicamente descendente.

Além do remodelamento do estojo córneo (Figuras 8, 9 e 10), o remodelamento do fluxo digital sanguíneo pode ser corroborado pela avaliação da venografia digital. Os venogramas digitais são usados para se obter informação sobre as veias que se comprimem por tecidos moles e/ou ósseos que se deslocam.

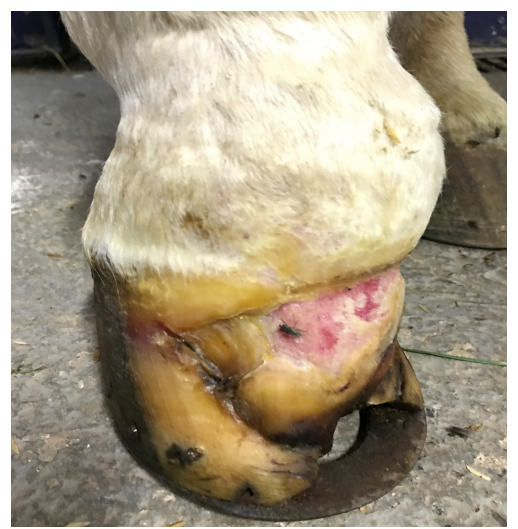

Figura 8A - Remodelamento do estojo córneo três meses após afecção ao dígito. 


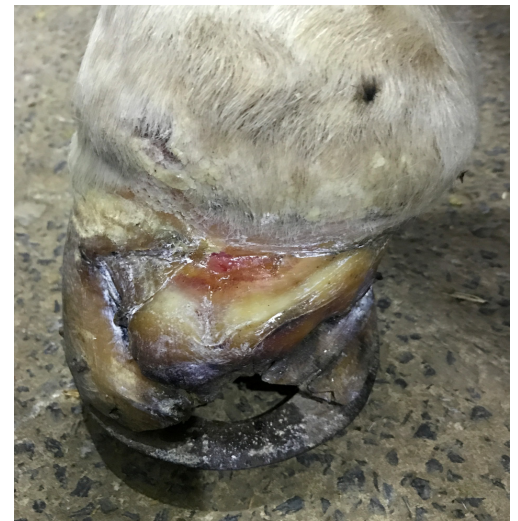

Figura 9 - Formação do novo córium. Imagem realizada 4 meses após recebimento do animal no HVET-UnB.

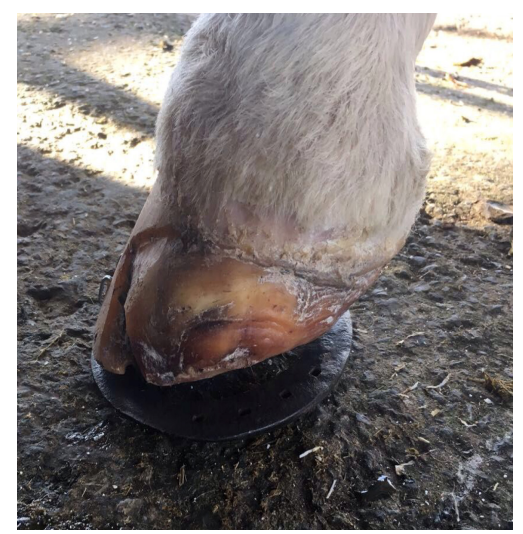

Figura 10 - Cinco meses depois, nota-se progressivo remodelamento do estojo córneo.

A venografia retrógrada no dígito tem sido descrita usualmente em casos de laminite, mas também em cavalos com dor crônica de dígito, associada a anormalidades de conformação da cápsula córnea e/ou orientação anormal da terceira falange. A venografia retrógrada permite o acesso ao arco terminal, plexo coronário, vasos laminares dorsais, vasos circunflexos e vasos da região do bulbo do talão, fornecendo avaliação sobre a gravidade das mudanças vasculares, bem como prevendo afecções ósseas (Butler et al., 2017). Observou-se no presente caso que os vasos circunflexos, o bulbo do talão e os vasos laminares dorsais foram alterados, e provavelmente o arco terminal também, visto a relação direta deste com os vasos laminares dorsais.
A integridade ameaçada do bulbo do talão pode ser explicada pelo percurso da artéria bulbar (plantar ao metatarso) e pelo fato de a maior parte do dano tecidual e carga mecânica do dígito ocorrerem na região anterior da parede do casco, conforme citado por Sales (2017). Segundo Rucker (2007), em casos de início de laminite, a região dos vasos circumflexos é, na maioria dos casos, a primeira do dígito a ficar comprometida. Neste caso, entretanto, não se sabe se a mesma também é a primeira afetada em quadro de osteíte infecciosa.

Feridas perfurantes através da sola do dígito, resultando em osteíte infecciosa da superfície solear da terceira falange, podem, inicialmente, aparecer como área de radioluscência do osso (Butler et al., 2017). Nas figuras 3 e 4 estas áreas de lucência podem ser notadas nas projeções DP e LM por suas margens irregulares e certa quantidade de opacidade aumentada as cercando, embora nova formação óssea esteja presente. É possível que hajam sinais de inflamação óssea crônica, incluindo perda de radiopacidade focal ou generalizada.

Morfologicamente, o diagnóstico se baseou em pododermatite ulcerativa necro-supurativa. Os achados histopatológicos são compatíveis com inflamação supurativa da derme e provavelmente possuem etiologia bacteriana. Feridas profundas no membro distal frequentemente podem envolver estruturas sinoviais, como a bainha digital tendínea, bursa do navicular e/ou a articulação interfalangeana distal. Dada a localização destas feridas, uma infecção polimicrobiana pode ser esperada. Desta forma, a associação de penicilina/ ceftiofur e gentamicina/amicacina pode ser indicada nos casos de tecidos do membro distal e do dígito (Schumacher e Stashak, 2008).

Neste caso, a utilização de penicilina benzatina associada à gentamicina promoveu boa recuperação dos parâmetros hematológicos e bioquímicos do paciente. A perfusão regional com gentamicina e dimetilsulfóxido também promoveu fornecimento maximizado de fármaco antimicrobiano ao dígito acometido, sem nenhum possível comprometimento sistêmico, assim como citam Mills et al. (2000), Scheuch et al. (2002) e Mattson et al. (2004).

Uma vez que o córium esteja queratinizado, o uso da bandagem não se faz mais necessário, desde que 
seja feita inspeção diária da área lesionada. Injúrias de avulsão, laceração ou aquelas decorrentes de brocas ou culminando em osteíte podal tipicamente necessitam de aplicação de algum tipo de ferrageamento corretivo, de forma a se fornecer apoio (Figura 11) que não mais é providenciado pelo próprio casco do animal (Fitzgerald e Honnas, 2009). 0 ferrageamento oval ou o de coração podem ser utilizados, dependendo da gravidade da lesão, sendo necessários até que a completa integridade e força soleares tenham sido alcançadas. No presente caso, a utilização da ferradura oval foi importante para o animal, permitindo apoio e direcionamento do crescimento do casco.

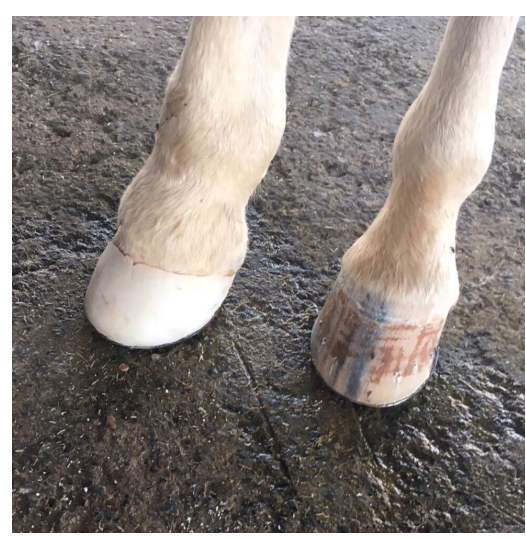

Figura 11 - Massa de acrílico temporária para melhor apoio e suporte de peso ao paciente, modelada 5 meses após atendimento inicial.

Como previamente discutido, a progressiva eclosão do estojo córneo em direção oposta ao que é comumente observado indicou um aparente fluxo laminar ascendente, provavelmente devido ao fornecimento constante de novas células na região lamelar distal, gerando epitelização e remodelação do córium. Esta reorganização promoveu considerável diminuição de secreção. Entretanto, a proliferação de células nesta região, como citado por Pollitt (2004), é rara quando comparada àquela promovida na região proximal da muralha do casco.

Após um ano da avaliação inicial, observou-se adaptação satisfatória do animal à nova conformação do estojo córneo do membro acometido, embora a claudicação, reduzida a grau 3, seja permanente e, em termos radiográficos, ainda haja reação óssea ativa na região.

\section{Conclusão}

Os estudos aqui citados foram feitos, sumariamente, em equinos relativamente saudáveis, sem lesões podais graves como a do caso relatado. Desta forma, pode-se sugerir que neste animal, as próprias células germinativas, em especial as da região laminar distal, tenham se reorganizado e promovido um fluxo laminar oposto, sinalizando maior ancoramento pelo aumento no número de desmossomos. Isto possivelmente resultou em zonas mais fortes de anexação entre as membranas celulares de queratinócitos adjacentes, com concomitante epitelização e remodelação do córium, promovendo considerável diminuição de secreção e redução da claudicação para grau 3.

\section{Referências}

Bertram JE, Gosline JM. Functional design of horse hoof keratin: the modulation of mechanical properties through hydration effects. J Exp Biol. 1987;130:121-36.

Bowker RM, Van Wulfen KK, Springer SE, Linder KE. Functional anatomy of the cartilage of the distal phalanx and digital cushion in the equine foot and a hemodynamic flow hypothesis of energy dissipation. Am J Vet Res. 1998;59(8):961-8.

Butler AJ, Colles CM, Dyson SJ, Kold SE, Poulos PW. Clinical radiology of the horse. Oxford: Wiley Blackwell; 2017. p. 79-80, 111-12.

Daradka M, Pollitt CC. Epidermal cell proliferation in the equine hoof wall. Equine Vet J. 2004.36(3):236-41.

Fitzgerald BW, Honnas CM. Management of Wounds in the Foot. In: Robinson NE, Sprayberry K. Current Therapy in Equine Medicine. St. Louis, MO: Saunders Elsevier; 2009. p. 535-40. 
Leach, D. H. The structure and function of the equine hoof wall, Saskatchewan. [dissertação]. Saskatoon: University of Saskatchewan; 1980. p. 37-8.

Mattson S, Bouré L, Pearce S, Hurtig M, Burger J, Black W. Intraosseous gentamicin perfusion of the distal metacarpus in standing horses. Vet Surg. 2004;33(2):180-6.

Mills ML, Rush BR, St Jean G, Gaughan EM, Mosier D, Gibson E, et al. Determination of synovial fluid and serum concentrations, and morphologic effects of intraarticular ceftiofur sodium in horses. Vet Surg. 2000;29(5):398-406.

Pollitt CC. Anatomy and physiology of the hoof inner wall. Clin Tech Equine Pract. 2004;3(1):3-21.

Pollitt CC. Equine laminitis. Current concepts. Publication No. 08/062. Project No. RIRDC UQ-118A. Kingston, ACT: Rural Industries Research and Development Corporation; 2008. p. 14-40.
Rucker A. The Digital Venogram. In: Floyd AE, Mansmann RA. Equine Podiatry. St. Louis, MO: Saunders; 2007. p. 328-46.

Sales JVF. Alterações venográficas podais em equinos [dissertação]. Brasília; Universidade de Brasília; 2017. p. 8,12 .

Scheuch BC, Van Hoogmoed LM, Wilson WD, Snyder JR, MacDonald MH, Watson ZE, et al. Comparison of intraosseous or intravenous infusion for delivery of amikacin sulfate to the tibiotarsal joint of horses. Am J Vet Res. 2002;63(3):374-80.

Schumacher J, Stashak TS. Management of wounds of the distal extremities. In: Stashak TS, Theoret CL. Equine Wound Management. Ames, IA: Wiley-Blackwell; 2008. p. 376, 401- 8. 